\section{Commentary: Collaborative education in surgery}

\author{
James I. Fann, MD
}

Critical to the success of many endeavors, collaborative synergy engages participants to achieve outcomes that each cannot accomplish individually, guided by transformative leadership to make and expand connections beyond defined limits. ${ }^{1}$ Instead of harkening back to the time of when "we were on call all the time," senior thoracic surgery leadership must recognize that there is an increasing need for collaborative synergy in our approach to resident education. Over the past 5 years, advancing surgical education has become more siloed, resulting in partial commitment of faculty at best and relative inactivity at worst. There are many reasons for less attention to the principles of surgical education-from the push for greater clinical productivity in the current (and future) health care system to lack of training in how to best teach at the level of individual faculty. Nowadays, it is unlikely that a faculty member goes home at night thinking about how to better train residents.

The Joint Council on Thoracic Surgery Education (JCTSE), founded in 1996 and incorporated in 2008, was "to advance thoracic surgery education.,",3 After its dissolution in 2016, presumably because of its resource requirement and perceived insufficient return on investment based on arbitrary educational and financial metrics, novel approaches to thoracic surgical education have been spearheaded by a few individuals with few resources. Previously, national and international collaboration was championed by the JCTSE with attention on deliverables, many of which generated high levels of resident and faculty involvement but lacked the

\footnotetext{
From the Department of Cardiothoracic Surgery, Stanford University, Stanford, Calif. Disclosures: The author reported no conflicts of interest.

The Journal policy requires editors and reviewers to disclose conflicts of interest and to decline handling or reviewing manuscripts for which they may have a conflict of interest. The editors and reviewers of this article have no conflicts of interest.

Received for publication Dec 3, 2019; revisions received Dec 3, 2019; accepted for publication Dec 3, 2019; available ahead of print March 7, 2020.

Address for reprints: James I. Fann, MD, Department of Cardiothoracic Surgery,

Stanford University, 300 Pasteur Dr, Stanford, CA 94305 (E-mail: jfann@ stanford.edu).

JTCVS Techniques 2020;3:245-6

2666-2507

Published by Elsevier Inc. on behalf of The American Association for Thoracic Surgery. This is an open access article under the CC BY-NC-ND license (http:// creativecommons.org/licenses/by-nc-nd/4.0/).

https://doi.org/10.1016/j.xjtc.2020.03.001
}

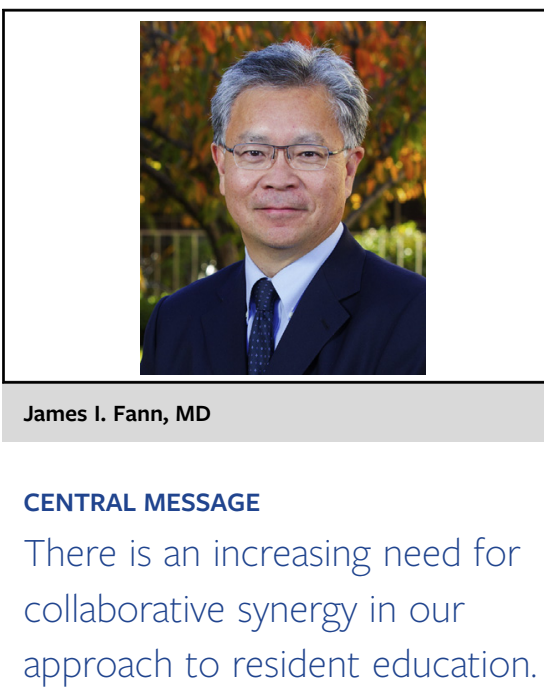

ability to be monetized. Like any educational enterprise viewed from a business perspective, the efforts of JCTSE effectively became appendages of larger organizations. Missing now is the collaborative synergy. By default, many current educational products are in the purview of the wellorganized Thoracic Surgery Residents Association, ${ }^{4}$ effectively relying on residents to train residents.

Professor Sergeant initiated his training paradigm years ago because of the identified need in the European environment. $^{5}$ With many disparate programs in Europe, he sought to standardize components of basic technical skills training, such as vessel anastomosis, and personally visited numerous international sites with the sole purpose of advancing and oftentimes learning from such training. No doubt, this is an expensive proposition, as evidenced by the need for industry sponsorship. Likewise, in the United States, the Boot Camp technical skills initiative continues with participation from identified surgeons interested in education supplemented with support from the Thoracic Surgery Directors Association, Society of Thoracic Surgeons, and industry. ${ }^{6}$ But many have questioned the efficacy of such massed-practice approach to training, the limitations of which are well recognized. What this collaborative environment does provide is a venue for residents to learn basic techniques and principles in a focused manner, to understand the need for distributed and deliberate practice, to compare themselves with other residents, and to interact with educators in our field-an opportunity that should not be undervalued. Surgical leaders have well-deserved reputations, and many purport to be involved in education with titles that go along with such endeavors. But their interactions with trainees in basic technical skills training 
may be limited and often only with those at their institutions. Leaders need to expand their sphere of influence, as intimated by Professor Sergeant. True, the JCTSE was handicapped by its cost and inability to meet externally defined return on investment. However, it did identify the educational needs and developed many meaningful solutions-importantly, it pushed for collaborative synergy. Sustaining such an effort requires continued support and transcends traditional metrics. Just look at the cost and challenges of K-12 education.

\section{References}

1. Collaborative synergy. Available at: https://www.igi-global.com/dictionary/ collaborative-synergy-leadership-business/4429. Accessed November 30, 2019.

2. Crawford FA Jr. Thoracic surgery education-past, present, and future. Ann Thorac Surg. 2005;79:S2232-7.

3. Verrier ED. Joint Council on Thoracic Surgical Education: an investment in our future. J Thorac Cardiovasc Surg. 2011;141:318-21.

4. Thoracic Surgery Residents Association. Available at: https://www.tsranet.org/. Accessed November 30, 2019.

5. Sergeant P, DeRaet J. Learning and training complex coronary surgery. J Thorac Cardiovasc Surg. 2020;3:240-4.

6. TSDA Boot Camp. Available at: https://tsda.org/the-tsda/boot-camp/. Accessed November 30, 2019. 